\title{
Environmental Impacts on the Strength Parameters of Mineral-Acrylic (PMMA/ATH) Facade Panels
}

\author{
Aleksander Byrdy and Michał Kołaczkowski \\ Building and Structure Physics Division, Institute of Building Materials and Structures, Faculty of Civil Engineering, \\ Cracow University of Technology, 31-155 Cracow, Poland \\ Correspondence should be addressed to Aleksander Byrdy; abyrdy@pk.edu.pl
}

Received 6 August 2015; Revised 15 November 2015; Accepted 17 November 2015

Academic Editor: Gonzalo Martínez-Barrera

Copyright ( 2015 A. Byrdy and M. Kołaczkowski. This is an open access article distributed under the Creative Commons Attribution License, which permits unrestricted use, distribution, and reproduction in any medium, provided the original work is properly cited.

\begin{abstract}
Composite mineral-acrylic panels consist in $80 \%$ of natural minerals produced from bauxite (aluminium hydroxides (ATH)) and in $20 \%$ from acrylic resin (polymethyl methacrylate (PMMA)). This material due to high usability is widely used in interior finishes. Recently, the mineral-acrylic panels have been used as external claddings of buildings. So far, there are several dozen elevations realized worldwide. Due to the variability of the strength parameters of PMMA acrylic resins depending on the environmental influence, a number of tests on samples of mineral-acrylic panels to verify their suitability for use in climate conditions in Central Europe were performed. The studies determined the change of the material parameters after being subjected to aging process in conditions of high temperature, high relative humidity, freeze-thaw cycles, and UV radiation. In the studies parameters such as flexural strength and modulus of elasticity were measured at a reference temperature of $23^{\circ} \mathrm{C}$. In raised and lowered temperatures only the tensile strength tests were conducted. Due to the lack of information in the available literature, the authors carried out tests of the temperature influence on the PMMA/ATH composite modulus of elasticity and flexural strength which is crucial in designing process.
\end{abstract}

\section{Introduction}

In modern architecture, for use on facades, materials with a wide functional range of designs, high strength, and durability are sought. One of such materials is composite mineral-acrylic panels (PMMA/ATH), which consist in $80 \%$ of natural minerals, produced from bauxite (aluminium hydroxides (ATH)) and in 20\% from acrylic resin (polymethyl methacrylate (PMMA)). These panels have a uniform, nonporous, homogeneous structure and are produced in a wide range of colors. They are easy to cut and stick together, and after suitable thermal treatment, they can be easily formed into various shapes. Because of these properties the PMMA/ATH panels represent a very attractive finishing material and for about 40 years have been commonly used as interior design elements. The use of mineral-acrylic panels on facades of buildings is subject to the development of modern techniques of cladding assembly. So far, there are several dozen mineral-acrylic panels elevations realized worldwide. Modern ventilated facades are made of panels of large size, fixed to a support substrate by means of a steel or aluminum understructure. Facade panels are nodal supported with mechanical undercut anchors deposited on the rear face of the panel (Figure 1).

An example of such a cladding may be that realized in 2014 from Corian panels, on the "Afrykanarium" building in Wrockaw. It has an area of over $6000 \mathrm{~m}^{2}$ and it consists of black panels, Corian Deep Nocturne, of the largest size used so far, that is, up to $5,2 \times 3,5 \mathrm{~m}^{2}$. In the first year of use of the cladding some damages were observed, like out of plane deformations in the summer and cracking in the winter (see Figure 2). In order to explain the causes of the damages, the authors examined the changes in durability of the panels in extreme climate conditions occurring in Central Europe.

\section{Materials and Methods}

2.1. Physicomechanical Parameters of the PMMA/ATH Panels. To implement modern ventilated PMMA/ATH claddings, 

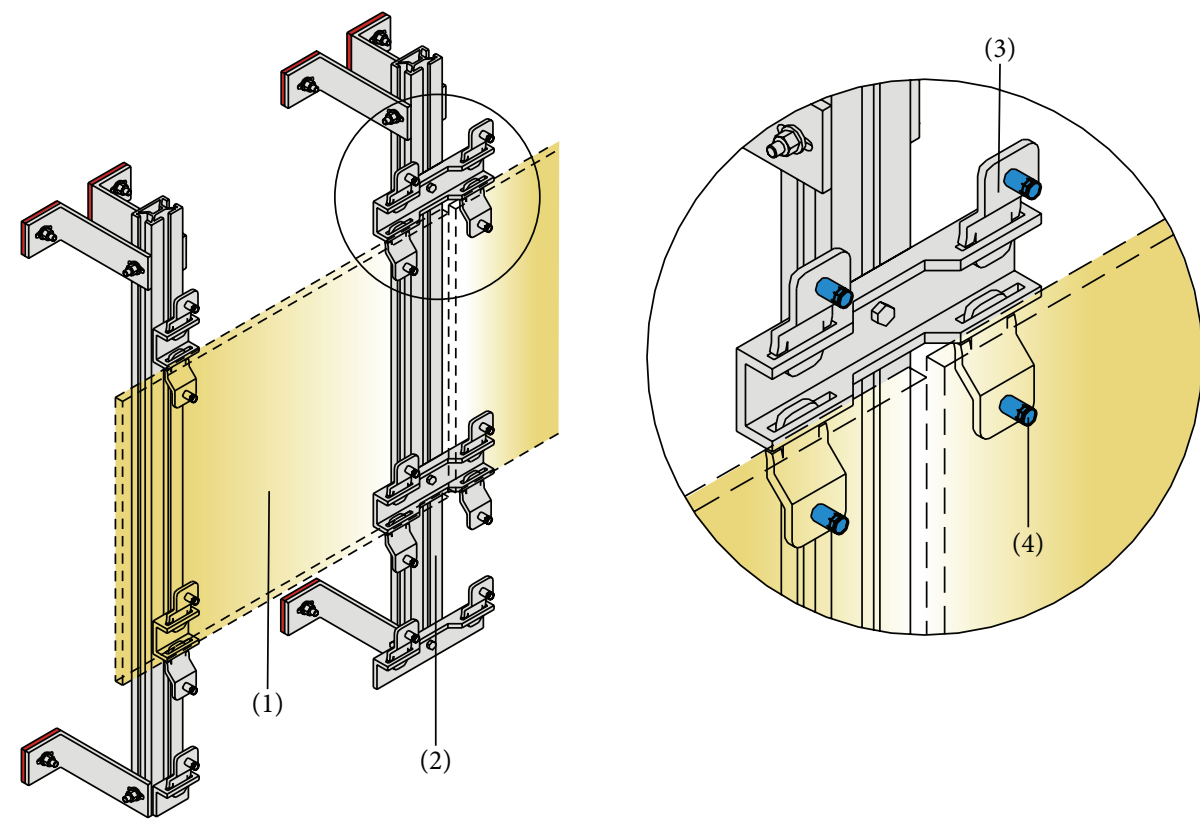

FiguRE 1: Example of understructure for fixing ventilated facade claddings. Designations: (1) facade panel, (2) steel-aluminum understructure, (3) holder fixing the facade panel, and (4) undercut fixing.

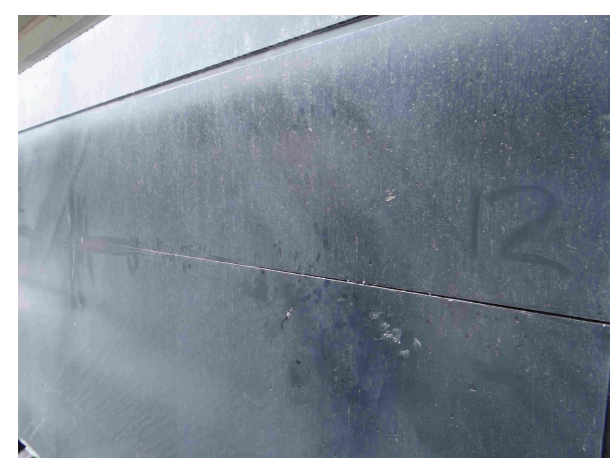

(a)

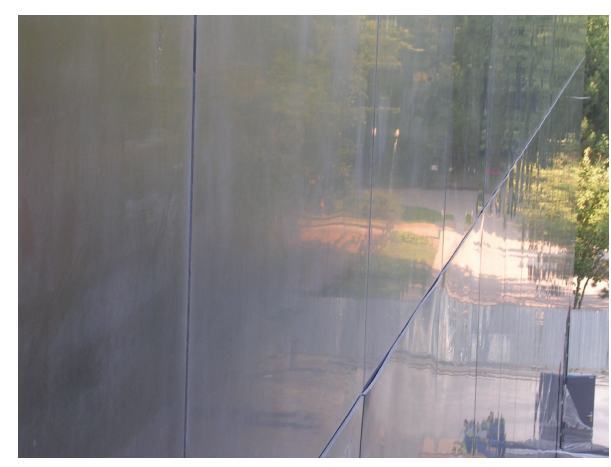

(b)

Figure 2: Damages of the Corian panels of "Afrykanarium” building in Wrocław: (a) cracking in the winter and (b) deformations of panel edges in the summer.

TABLE 1: Basic physicomechanical parameters of the acrylic-mineral (PMMA/ATH) panels.

\begin{tabular}{lc}
\hline Feature & Declared value \\
\hline Volume density $\left(\mathrm{kg} / \mathrm{m}^{2}\right)$ & $1680-1175$ \\
Water absorption by weight $(\%)$ & $0-1$ \\
Flexural strength $(\mathrm{MPa})$ & $57,1-74,0$ \\
Modulus of elasticity $(\mathrm{MPa})$ & $8040-9220$ \\
Coefficient of thermal expansion $(\mathrm{l} / \mathrm{K})$ & $2,0-3,7 * 10^{-5}$ \\
\hline
\end{tabular}

very thin panels with a thickness up to $2 \mathrm{~cm}$ are used. Due to the significant environmental loads, facade panels must meet high requirements for physicomechanical characteristics. The range of the basic physicomechanical parameters of the panels from different manufacturers is shown in Table 1.
2.2. Environmental Loads Acting on Facade Panels. One of the major loads acting on the facade panels is a thermal load. Changes in temperature of cladding panels depend on ambient temperature, solar radiation, solar radiation absorption coefficient of the material, geographic location, exposure of an elevation relative to the world sides, and layering of a wall on which the panels are attached. Darkcoloured panels, directed to the south and south-west, are subjected to a high sunlight absorption and are heated to much higher temperatures than the ambient temperature. Sample record of temperature changes on the surface of the black Corian Deep Nocturne panels measured by the authors is shown in Figure 3.

Based on the studies of the facade with a ventilated gap, it was found that the temperature of the plates from the side of the air gap is lower by $7-12^{\circ} \mathrm{C}$ than the sunlit 
TABLE 2: The average strength characteristics resulting from aging tests of Corian (PMMA/ATH) panels [4].

\begin{tabular}{lcc}
\hline Method of testing & Flexural strength (MPa) & Modulus of elasticity (MPa) \\
\hline Preliminary parameters & 69,4 & 9253 \\
\hline $\begin{array}{l}\text { Aging by the influence of constant temperature }(65 \pm 3)^{\circ} \mathrm{C} \text { and } \\
\text { a relative humidity close to } 100 \% \text { for } 28 \text { days }\end{array}$ & 50,7 & 8360 \\
\hline $\begin{array}{l}\text { Aging for } 3 \times 1000 \text { hours, in } 40^{\circ} \mathrm{C} \text { and } 50 \% \text { relative humidity, } \\
\text { UV } 550 \mathrm{~W} / \mathrm{m}^{2} \text {, water pouring every } 100 \text { minutes for } 18 \text { minutes }\end{array}$ & 65,0 & 9543 \\
\hline Cycles of freezing and thawing, 100 cycles & 70,2 & 8833 \\
\hline
\end{tabular}

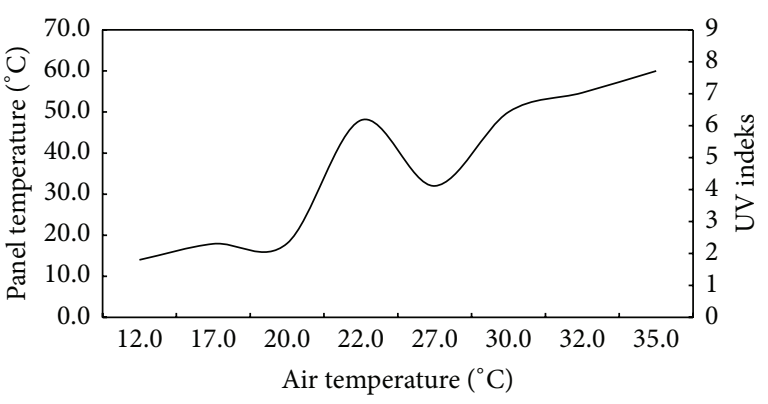

Figure 3: Temperature of the outer surface of Corian Deep Nocturne (PMMA/ATH) black facade panels mounted on the southern wall, read between 27.07.13 and 20.09.13 in Wrocław.

surface temperature. In Central Europe the most vulnerable to thermal load are horizontal claddings and facades oriented towards the south and south-west. On the basis of the calculation model of Mackey and Wright [1] as well as local meteorological data, it was determined that the maximum temperature that can be reached by PMMA/ATH facade panels located in Central Europe is $82.6^{\circ} \mathrm{C}$. Such a high temperature can cause not only significant thermal deformation of a cladding but also effects in changes of the strength characteristics of the mineral-acrylic panels $[2,3]$.

Facade panels are also subject to various other environmental factors such as high moisture and UV radiation and the most important factor, wind load. Bending stress caused by wind load is crucial in designing process and therefore the most important parameter of the material is its flexural strength.

As the plate material is characterized by high thermal expansion, the use of panels of this material requires the installation of sliding supports. Disabling of a free expanding and shrinking of panels subjected to temperature changes might cause very high longitudinal forces leading to distortion of a cladding look. Sliding mount of cladding panels makes the longitudinal forces resulting only from the selfweight of panels and thus being of little importance in the design process. Due to the low effort caused by tensile stress creeping of the material is of secondary importance when sizing plates.

Practically used supports, however, do not provide total freedom of move, because of the occurrence of frictional forces. Those supports fulfill their role because their susceptibility to move is substantial in comparison with the rigidity of the supported element. In the case of the cladding of the Wrocław "Afrykanarium," it was questioned if due to environmental condition changes the material's modulus of elasticity has not been so seriously decreased that the panels rigidity turned out to be too low, in comparison to resistance caused by the frictional forces in the supports. This could result in lack of free move and deformation of the panels, expanding under heating.

The authors performed the studies of Corian samples in order to determine the modulus of elasticity in different climate conditions and to determine if the observed cladding deformations might occur due to decrease of rigidity in the elevated temperature, despite fixing in accordance with the engineering design.

Variation of flexural strength of Corian samples under different environmental conditions was examined in order to determine the actual bearing capacity of panels under wind load in different conditions as well as verification of the safety of the "Afrykanarium" cladding.

The calculations should also be base for drawing practical conclusions about designing of new elevations using PMMA/ATH panels.

\section{Results and Discussion}

3.1. Results of Studies Described in Available Literature. In order to check the influence of environment on Corian (PMMA/ATH) panels strength parameters, several aging studies verifying their suitability for use on exterior facades were performed, CSTB Report [4]. Components with dimensions of $260 \times 20 \times 13 \mathrm{~mm}$ were selected for the study. The reference trial included 10 samples, whereas each ageing test included 5 samples. The samples were aged at a constant, elevated temperature about $65^{\circ} \mathrm{C}$ and under a constant, high relative humidity close to saturation for a period of 28 days. The next test consisted in subjecting the panels to a $\mathrm{UV}$ radiation of $550 \mathrm{~W}$ intensity at $40^{\circ} \mathrm{C}$ and $50 \%$ relative humidity. Total run time of the test was 3000 hours, during which water was poured over the plate periodically (every 100 minutes for 18 minutes). In order to test the effect of freezing and thawing on the strength properties of Corian panels a total of 100 cycles of freezing and thawing of the samples were carried out according to the procedure described in European Standard EN ISO 10545-12:1997 [5]. Verification of the effect of the environment on the material consisted in testing the changes in flexural strength and modulus of elasticity upon bending. The studies whose results are shown in Table 2 ended with strength tests performed at $23^{\circ} \mathrm{C}$ for 


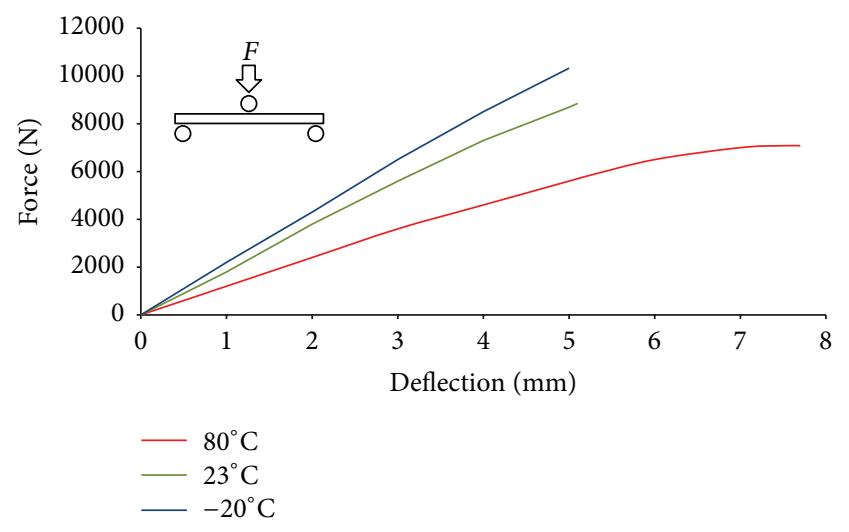

FIGURE 4: Plot of the average load-deflection relationships for Corian (PMMA/ATH) panels subjected to concentrated-load bending at various ambient temperatures.

comparison with the results of the preliminary studies of the material.

It should be emphasized that there are no studies described in the available literature that include PMMA/ATH panels flexural strength measurement at raised temperatures. Temperature changes have a significant impact on the strength parameters of acrylic-mineral panels. A study of tensile strength of PMMA/ATH panels carried out by Nie et al. [6] demonstrated a significant decrease in tensile strength of heated samples of the material. At a temperature of $90^{\circ} \mathrm{C}$, nearly $70 \%$ lower tensile strength than at $25^{\circ} \mathrm{C}$ was recorded. Together with tensile strength decrease at elevated temperature there was a decrease of modulus of elasticity of the material.

3.2. Results of Studies Carried out by Authors. According to a study of Marshall and Evans [7] permissible strains determined in the bending and stretching test may be different and therefore the authors decided to determine the effect of temperature changes on the PMMA/ATH panel flexural strength. In order to verify the effect of temperature on strength parameters, panels were subjected to concentratedload bending tests at temperatures of $-20^{\circ} \mathrm{C}, 23^{\circ} \mathrm{C}$, and $80^{\circ} \mathrm{C}$. Tests were carried out in testing machine for bending test with climate chamber. For each series of tests, 10 samples with dimensions $250 \times 250 \times 12 \mathrm{~mm}$ were used. Samples were supported by hinged linear supports in the spacing of $200 \mathrm{~mm}$ (see static scheme on Figure 4). Studies were performed on the Corian Deep Nocturne panels. The resistance to bending tests was carried out using the rate of change of panel's deflection set to $5 \mathrm{~mm} / \mathrm{min}$. Samples for testing at reduced or elevated temperature were conditioned for 2 hours before the test in order to reach the right temperature throughout the entire cross section of the sample. Conditioning time of the samples was adopted on the basis of earlier measurements of changes in the internal temperature of the samples with a thermocouple mounted in an opening formed in the sample. The average test results are shown in Table 3 and in Figure 4.
TABLE 3: The average results of the strength test of the Corian (PMMA/ATH) panels at different temperatures.

\begin{tabular}{lcc}
\hline Method of testing & $\begin{array}{c}\text { Flexural } \\
\text { strength }(\mathrm{MPa})\end{array}$ & $\begin{array}{c}\text { Modulus of } \\
\text { elasticity }(\mathrm{MPa})\end{array}$ \\
\hline Parameters at $23^{\circ} \mathrm{C}$ & 82,05 & 8010 \\
Parameters at $-20^{\circ} \mathrm{C}$ & 83,3 & 9886 \\
Parameters at $+80^{\circ} \mathrm{C}$ & 57,7 & 5793 \\
\hline
\end{tabular}

3.3. Studies Results Summary. On the basis of the test results shown in Tables 2 and 3, the following changes in flexural strength of PMMA/ATH Corian panels were determined:

(i) panels aged for 28 days in $65^{\circ} \mathrm{C}$ and under the saturated vapor-26,9\% decrease,

(ii) panels subjected to aging by UV radiation-6,3\% decrease,

(iii) panels with temperature of $-20^{\circ} \mathrm{C}-1,5 \%$ increase,

(iv) panels with temperature of $80^{\circ} \mathrm{C}-29,7 \%$ decrease.

Studies of Corian panels in cycles of freezing and thawing did not show changes in the strength characteristics of the material.

Changes in elastic modulus were observed mainly as a result of temperature changes. Changes in the elastic modulus were measured for $30 \%$ of the effort of the element and were as follows:

(i) panels aged for 28 days in $65^{\circ} \mathrm{C}$ and under the saturated vapor- $9,6 \%$ decrease,

(ii) panels with temperature of $-20^{\circ} \mathrm{C}-23,4 \%$ increase,

(iii) panels with temperature of $80^{\circ} \mathrm{C}-27,7 \%$ decrease.

\section{Conclusion}

The results of the tests carried out by the authors showed a significant reduction in the flexural strength of the material under the influence of the raised temperature. The reduction was relatively lower than in the case of tensile strength measured by Nie et al. [6], nonetheless it was significant which is of a high practical importance. Another important factor to reduce the bending strength is aging at elevated temperature and humidity, which was described in [4].

In the case of the analyzed facade, even under significantly reduced bending strength, the calculated resistance of the panels to bending by the wind proved to be sufficient.

The performed studies of the Corian panels allowed us to conclude that, in the case of the described elevation, the recorded changes of strength parameters of the cladding panels were not the direct cause of their damage.

Based on the computational analysis, it was found that if the support was performed according to the design, even the panels under reduced modulus of elasticity would be provided with the correct sliding support. The observed deformations of the panels during the summer were caused by blockage of move due to the implementation of the supports in a manner inconsistent with the project. The 
observed cracking of panels joints during the winter was caused by inadequate technology of gluing edges of the panels.

The size of changes of strength characteristics of PMMA/ ATH panels resulting from environmental influences depends on the composition and structure of the material [8]. For this reason, the basis for the use of mineral-acrylic panels of particular manufacturer on external facades should be broad studies of the impact of the environment on their mechanical properties. The results of the tests described in the available literature concern PMMA/ATH mechanical properties changes only at elevated temperatures. Bending tests carried out by the authors on Corian samples at $-20^{\circ} \mathrm{C}$ showed improvement in the strength parameters of the material in lowered temperature (Table 3) and a ductile form of the material destruction as in the case of higher temperatures.

To obtain strength characteristics of the PMMA/ATH panels, being the most useful for the design process, aging tests should be performed with the final measurement of the material properties at $80^{\circ} \mathrm{C}$. Strength values obtained this way best reflect actual properties of the panels needed to model their work while using the facade. As a result of these studies, a partial factor for the strength properties of mineralacrylic panels intended for a use on exterior facades should be developed.

Further studies of PMMA/ATH panels should be based on observation of their strength properties in natural conditions. The results of these studies may be the basis for the development of predicted properties changes in time, analogously to the proposal for their modeling published by Santos et al. [8].

\section{Conflict of Interests}

The authors declare that there is no conflict of interests regarding the publication of this paper.

\section{Acknowledgment}

This work was partially funded by Project L-1/271/DS/2014.

\section{References}

[1] C. Mackey and L. Wright, "Periodic heat flow-composite walls or roofs," Transactions of the American Society of Heating and Ventilating Engineers, vol. 52, pp. 283-296, 1946.

[2] C. Basaran, S. Nie, and C. S. Hutchins, "Time dependent behavior of a particle filled composite PMMA/ATH at elevated temperatures," Journal of Composite Materials, vol. 42, no. 19, pp. 2003-2025, 2008.

[3] E. Gunel and C. Basaran, "Influence of filler content and interphase properties on large deformation micromechanics of particle filled acrylics," Mechanics of Materials, vol. 57, pp. 134146, 2013.

[4] Centre Scientifique et Technique du Bâtiment (CSTB), "Marnela-Vallée," Rapport d'Essais CLC 09-26016148/26022557, Centre Scientifique et Technique du Bâtiment (CSTB), 2010.
[5] International Organization for Standardization, "Ceramic tiles. Determination of frost resistance," EN ISO 10545-12:1997, International Organization for Standardization, 1997.

[6] S. Nie, C. Basaran, C. S. Hutchins, and H. Ergun, "Failure mechanisms in PMMA/ATH acrylic casting dispersion," Journal of the Mechanical Behavior of Materials, vol. 17, no. 2, pp. 79-96, 2006.

[7] D. B. Marshall and A. G. Evans, "Failure mechanisms in ceramic-fiber/ceramic-matrix composites," Journal of the American Ceramic Society, vol. 68, no. 5, pp. 225-231, 1985.

[8] R. M. Santos, G. L. Botelho, C. Cramez, and A. V. Machado, "Outdoor and accelerated weathering of acrylonitrile-butadiene-styrene: a correlation study," Polymer Degradation and Stability, vol. 98, no. 10, pp. 2111-2115, 2013. 

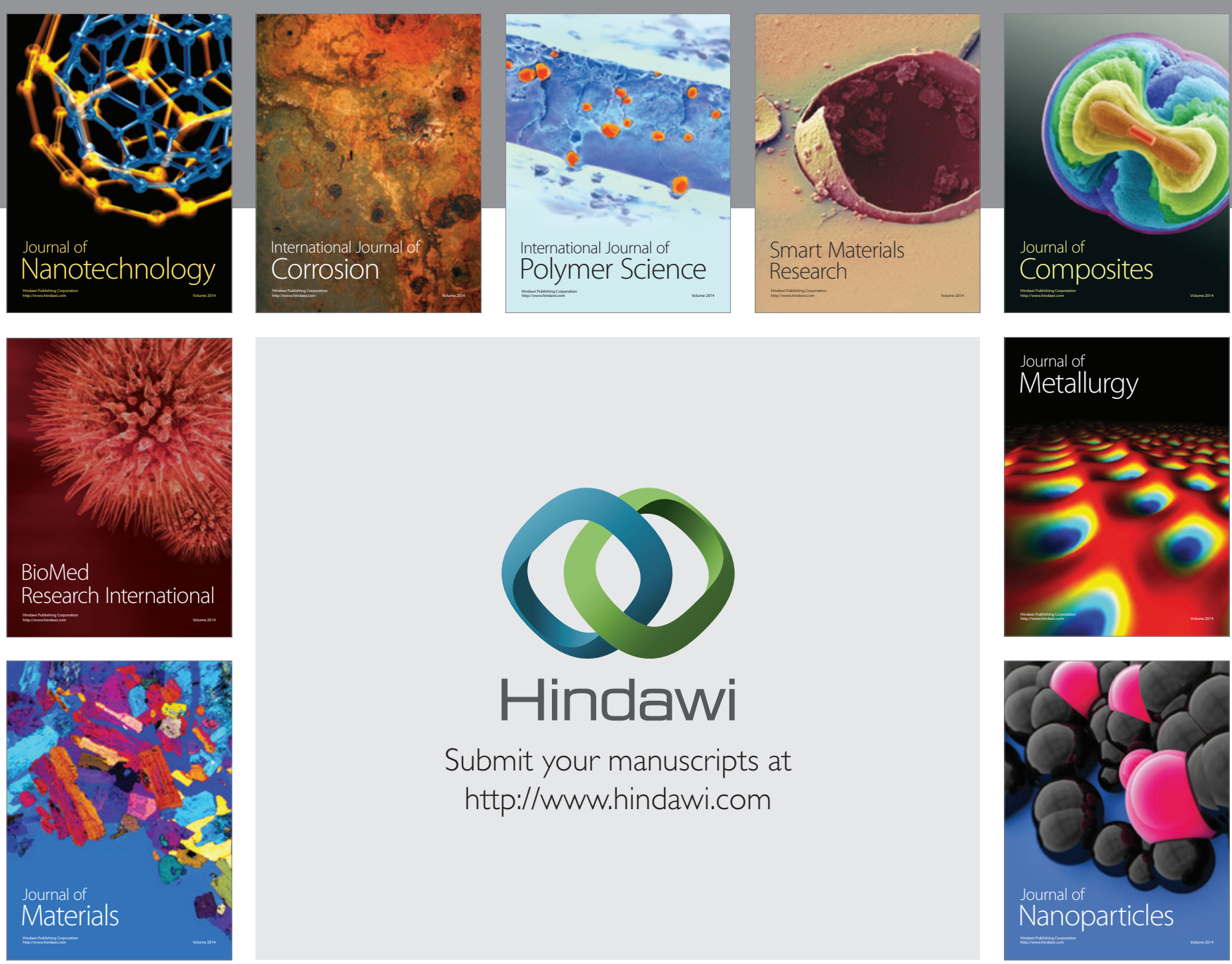

Submit your manuscripts at http://www.hindawi.com
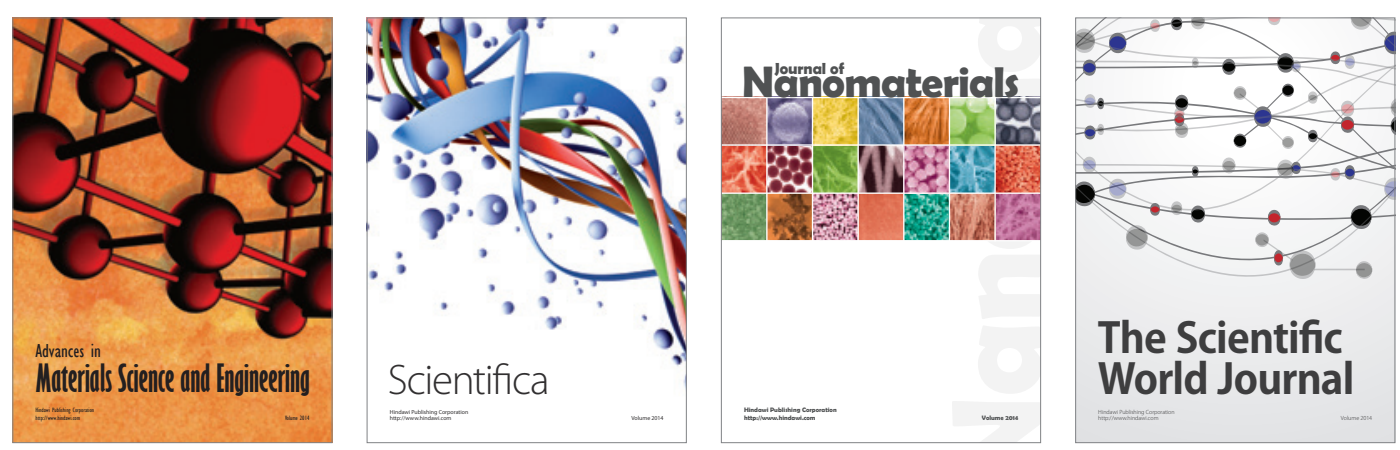

\section{The Scientific World Journal}
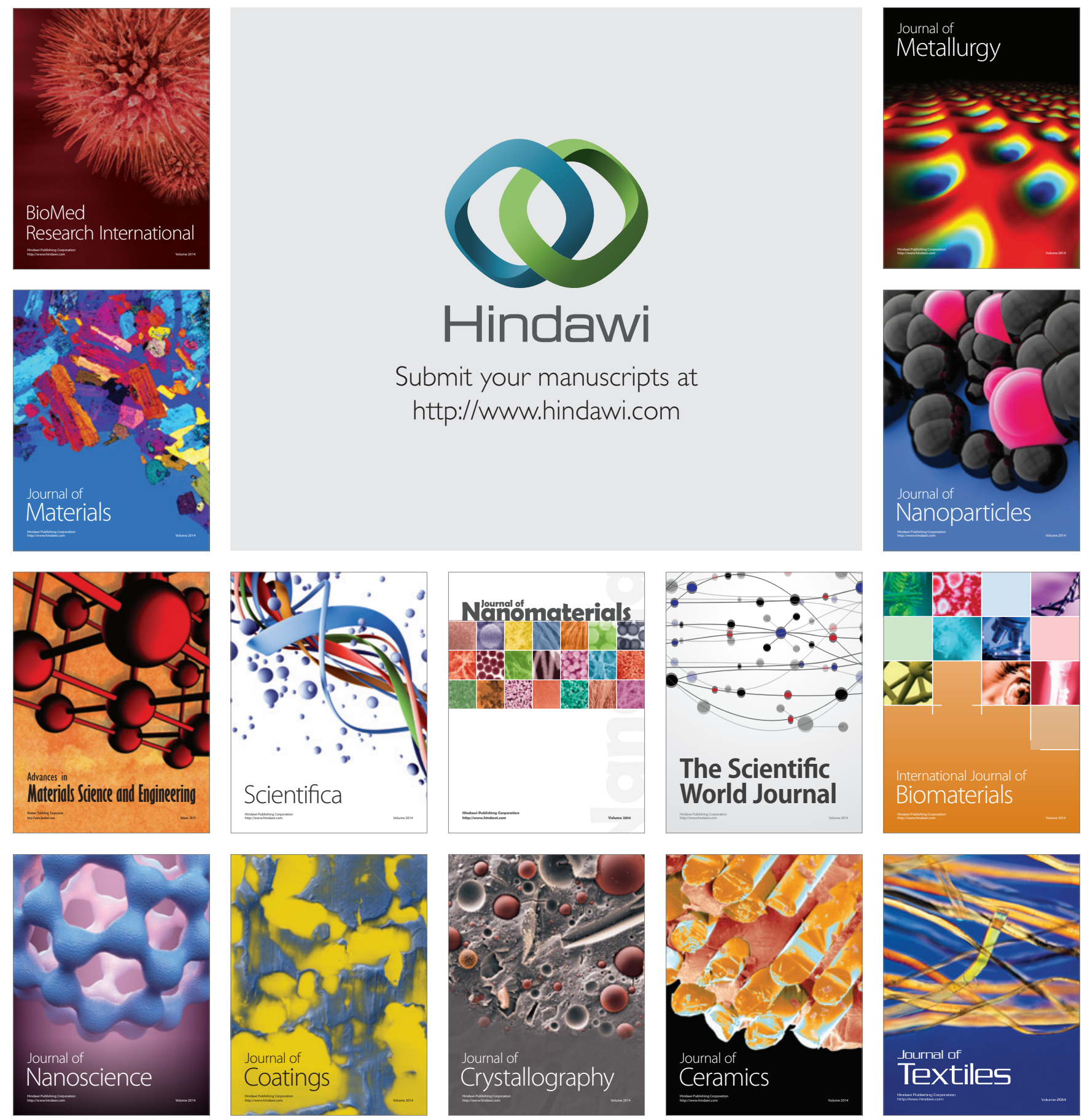